\title{
Reproductive System Findings Time Point Reference
}

National Cancer Institute

\section{Source}

National Cancer Institute. Reproductive System Findings Time Point Reference. NCI

Thesaurus. Code C162213.

The point in time that acts as a fixed reference point to a reproductive system finding. 